\title{
Erratum to: Open versus robotic-assisted partial nephrectomy: a multicenter comparison study of perioperative results and complications
}

\author{
Andrea Minervini - Gianni Vittori - Alessandro Antonelli $\cdot$ Antonio Celia • \\ Simone Crivellaro $\cdot$ Donato Dente $\cdot$ Vincenzo Di Santo $\cdot$ Bruno Frea $\cdot$ \\ Mauro Gacci · Alberto Gritti · Lorenzo Masieri • Alessandro Morlacco • \\ Angelo Porreca - Bernardo Rocco - Paolo Parma - Claudio Simeone • \\ Stefano Zaramella $\cdot$ Marco Carini $\cdot$ Sergio Serni
}

Published online: 22 September 2013

(c) Springer-Verlag Berlin Heidelberg 2013

\section{Erratum to: World J Urol}

\section{DOI 10.1007/s00345-013-1136-x}

The author group was inadvertently published wrongly in the original publication of the article. The correct author group is provided here.

The online version of the original article can be found under doi:10.1007/s00345-013-1136-x.

A. Minervini · G. Vittori $(\bowtie) \cdot$ M. Gacci · L. Masieri .

M. Carini · S. Serni

Department of Urology, Careggi Hospital,

University of Florence, Florence, Italy

e-mail: giannivittori@yahoo.it

A. Antonelli · A. Gritti - C. Simeone

Department of Urology, University of Brescia, Brescia, Italy

\section{A. Celia}

Department of Urology, San Bassiano Hospital,

Bassano del Grappa, Italy

S. Crivellaro $\cdot$ B. Frea $\cdot$ A. Morlacco

Department of Urology, University of Udine, Udine, Italy

D. Dente - V. Di Santo - A. Porreca

Department of Urology, Hospital of Abano Terme, Padua, Italy

\section{B. Rocco}

Department of Urology, Regina Elena Hospital,

University of Milan, Milan, Italy

P. Parma

Department of Urology, Carlo Poma Hospital, Mantua, Italy

S. Zaramella

Department of Urology, Maggiore della Carità Hospital,

Novara, Italy 